\title{
QUANDO FOI MESMO QUE SAÍMOS DO EGITO? A SAGA DE ORLY CASTEL- BLOOM
}

\section{WHEN DID WE ACTUALLY LEAVE EGYPT? ORLY CASTEL-BLOOM'S SAGA}

Nancy Rozenchan*

Resumo: Setenta anos após a criação do moderno Estado de Israel em que nem todos os seus problemas foram solucionados mas, ao menos, foram enfrentados, muitos destes se expressam e se esclarecem por meio da literatura hebraica. Dentre estas questões destacam-se as migrações ocorridas durante estas sete décadas e a absorção dos recém-chegados que precisaram se adaptar à vida no país, desde a nova língua até novas conformações socioculturais. Os variados motivos para estas migrações também pesam sobre estes novos israelenses. O premiado romance Haroman hamitsri (O romance egípcio), de 2015, de Orly Castel-Bloom que, numa saga, trata da imigração da família Castil (sobrenome da sua família) do Egito a Israel, das origens sefarditas da mesma e da demolição de seus sonhos sionistas, servirá de modelo para seguir esta trajetória.

Palavras-chave: Orly Castel-Bloom. Haroman hamitsri. Romance hebraico. Literatura israelense. Literatura hebraica.

\begin{abstract}
Seventy years after the creation of the modern State of Israel in which not all of its problems were solved but at least they were faced, many of these are expressed and clarified through Hebrew literature. Among these issues are the migrations that occurred during these seven decades and the absorption of newcomers who needed to adapt to life in the country, from the new language to new socio-cultural conformations. The varied motives for these migrations also weigh on these new Israelis. The award-winning novel Haroman hamitsri (The Egyptian Romance), 2015, by Orly Castel-Bloom, which in a saga reports about the immigration of the Castil family (surname of her family) from Egypt to Israel, its Sefardites origins and the demolition of their Zionist dreams will be approached in order to follow this trajectory.
\end{abstract}

Keywords: Orly Castel-Bloom. Haroman hamitsri. Hebrew novel. Israeli literature. Hebrew literature.

Os setenta anos do Estado de Israel e o que significa viver no país são temas que, nesta data, ganham vigor e que aguçam o interesse por tudo o que lá se desenvolveu; quando se acessa a literatura hebraica que, em grande escala, registra, elabora e põe ao alcance do leitor a infinidade dos eventos e reflexões que construíram o país, a riqueza do que se lê é capaz de

\footnotetext{
* Professora Sênior do Departamento de Letras Orientais e Professora Colaboradora do Programa LETRA de PósGraduação do Departamento de Letras Modernas da FFLCH da Universidade de São Paulo. Email: <nrozench@usp.br>.
} 
satisfazer os mais ávidos leitores. A par do que foi a luta pela criação, construção e desenvolvimento da nova nação, o que ocorreu e o que se desenrola atualmente com sua população constitui o grande equipamento desta literatura; a forma desta escrita, em que muitos autores se esmeram, contribui para o seu sucesso e reconhecimento internacional.

A literatura ficcional hebraica no solo israelense não é muito antiga, tem pouco mais de cem anos. A diversidade das populações que vieram a compor o moderno Estado, assim como a variedade dos antecedentes e origem dos autores conferem às inúmeras obras uma fartura de assuntos e abordagens bastante significativas. Os principais estudiosos da matéria esmeraramse em criar classificações por períodos e temas que facilitassem a compreensão da amplidão do que se escreve na língua ancestral revivida intensamente no antigo solo. A elas somam-se subclassificações que são essenciais para dar conta da tarefa de abordar as escritas. Gêneros, como romances de imigração, são constantemente enriquecidos com novos aportes.

Na primeira metade do século $\mathrm{XX}$, as primeiras ondas imigratórias a formar a nova população do país, as aliyot, trouxeram principalmente judeus do Centro e Leste europeus, os ashquenazitas, e foram estes que forjaram a literatura hebraica do início do século XX. O país contava, então, com expressiva população árabe e havia habitantes sefarditas provenientes de países da Europa Mediterrânea e judeus vindos de países árabes, que viriam a ser designados de mizrachim, orientais. O número de sefarditas e de mizrachim era muito restrito; não foram então tema essencial na cultura, sua representação na literatura foi mínima assim como o número de autores provenientes desses grupos foi ínfimo. Os árabes locais, apesar de numerosos, também não mereceram destaque.

Por volta da época em que foi declarada a existência do novo Estado de Israel, em meados do século passado, o número de habitantes judeus no país havia se ampliado, tendo como motivos adicionais ao aumento populacional natural a vinda de sobreviventes da II Guerra, com ou sem família, que não tinham mais onde se fixar no solo europeu onde o seu destino tinha sido selado, e o grande número de habitantes de países árabes, da África e do Oriente Médio, fugidos e/ou expulsos dos territórios em que tinham vivido por muitos séculos. O número de autores ashquenazitas continuava a ser o prevalecente, seus temas prendiam-se aos esforços e embates pela criação do país e integração de todos em prol da consolidação do mesmo, com a continuada abolição dos traços que os caracterizaram enquanto judeus diaspóricos. As populações que continuaram sendo minoritárias, ainda que fossem expressivas em número, ainda não gozavam de uma melhor posição nas letras hebraicas; aí incluíam-se agora sefarditas, marroquinos, iraquianos, sobreviventes da shoá. Em seus momentos mais complexos de 
integração no país e na sua cultura, estes filões da população não mereceram a devida atenção nem dos governantes e nem da literatura. Estes nichos populacionais não dispuseram, a não ser por raras exceções, de escritores que os representassem e nem os autores de destaque tratavam deles. Alguns autores recém-chegados, que eram provenientes do Iraque, e que já se dedicavam ali à escrita, não conseguiram, de imediato, proceder a uma troca de língua. Enquanto a sua língua de expressão continuou sendo o árabe, não angariaram leitores. O mesmo se deu com quem escrevia em ídiche. No caso desta língua, a pertinácia dos que se expressavam nela e o rico substrato cultural que subjazia a ela conseguiram fazer com que esta forma de expressão não soçobrasse, mas não mais do que isto. Os que se expressavam em judeu-espanhol (ladino) não gozaram de representação literária expressiva. Em geral, os assuntos que aviltaram os recém-chegados não eram trazidos à tona; vergonha, humilhação, sofrimentos foram abafados pelas autoridades e pelos próprios indivíduos que tinham passado por provações; além disso, o público nativo não lhes deu atenção. Construir a nação era primordial.

Nos anos 70, com mais uma guerra e seus reveses, mudança de linha de governança, dados demográficos apontando para o crescimento numérico das populações anteriormente colocadas à margem, novas possibilidades de expressão literária são atingidas; elas se manifestam pela ampliação do espaço que coube a estes grupos ocupar, tanto pelo número populacional como pela condição própria de surgimento de autores, como por se empenharem em ocupá-lo devidamente. Seus assuntos passam a despertar interesse, a ser tema central, e novos escritores, oriundos destas mesmas minorias, começam a conquistar espaço próprio. Os vieses diferentes se destacam, alguns deles acompanhando tendências de temáticas comuns a outros países: shoá, sobreviventes, mulheres, feminismo, homossexualismo, o árabe e, gradualmente, o palestino, os novos imigrantes etíopes e soviéticos, trabalhadores estrangeiros - filipinos e outros, sofrimentos. Por volta da passagem para o século XXI, no caso de ainda não terem sido descartadas pelo desgaste, estas temáticas chegam à segunda geração ou à geração seguinte de descendentes daqueles que sofreram por esta característica de que não tinham como se livrar; esta geração, que não mais carrega esses traços como fator identitário básico único, pode olhar para os seus próprios padrões de forma um pouco mais desapegada e, simultaneamente, está livre para abordá-los tão incisivamente quanto queira, objetiva, se assim o desejar, reclamar os seus direitos e reivindicar reparos, quando preciso. Mas estes operadores não estão dispensados de tomar posição, de expor feridas e cicatrizes e de protestar.

Escritores com longos anos dedicados à escrita, como A. B. Yehoshua e Amós Oz, passaram a assumir posições mais definidas quanto a temas que foram abafados ou 
dissimulados em momentos mais antigos de suas carreiras. A obra de Yehoshua, autor sefardita, que começou a ser publicada em 1963, não indicava traços desta sua identidade. Isto somente começou a tomar forma cerca de quinze anos mais tarde, quando sefarditas e árabes já são metade dos seus personagens em O Amante (Hameahev) em 1977. Em O Senhor Máni (Mar Máni), de 1989, centrado em sefarditas, há árabes e até mesmo nazistas, quase não há mais personagens ashquenazitas. Na categoria de temas de sofrimento, em Oz, o suicídio da mãe, sublimado no seu primeiro romance, Meu Michel (Michael sheli), de 1968, volta com todas as letras e detalhes no grande romance autobiográfico De Amor e Trevas (Sipur ahavá vechôshech) de 2002. Caso semelhante ocorre com Orly Castel-Bloom, considerada a escritora mais audaciosa de sua geração; ela assume posições mais definidas quanto a temas que foram abafados ou dissimulados em momentos mais antigos de sua carreira. Em seu décimo quarto livro, trata das dores da saída do Egito e, principalmente, de quanto Israel pesou sobre os judeus egípcios ${ }^{1}$. Como nas demais imigrações de judeus a Israel, os dois aspectos foram dolorosos: a saída do Egito e a recepção em Israel. Vai uma grande distância de Dolly City $^{2}$, de 1992, obra que suscitou uma pequena revolução literária pela fragmentação deliberada de seu estilo, seu minimalismo e a violência de seu imaginário, a Haroman hamitsri ${ }^{3}$ (O Romance Egípcio), de 2015, quando a dor individual deu lugar a uma dor coletiva.

O romance Haroman hamitsri - ainda que seja difícil considerá-lo um romance, é constituído por um agrupado de relatos ou pequenos contos sem uma conexão obrigatória, que giram em torno de um centro inexistente, a maior parte dos quais se passa em Israel, alguns no Egito, na Espanha, e quase todos com referências ao passado, memórias aparentemente irrelevantes. A única consistência que o caracteriza é a posição "do contra" em relação a instituições como a família, a imigração, a memória, a história nacional ou o compromisso com as relações de sangue. Não tem personagem principal ou evento que ocorra em algum lugar ou

\footnotetext{
${ }^{1}$ A vida no Egito se reflete em obras em várias línguas de autores nascidos naquele país. No caso de autores israelenses, também escritores de segunda geração, nascidos em Israel, dedicaram-se ao tema. Em outras línguas, Andre Aciman, Jacqueline Kahanoff, Edmond Jabès, Paula Jacques, que escrevem em inglês (os dois primeiros) e em francês (os últimos) são os autores mais famosos. O psicanalista Jacques Hassoun foi autor do romance francês Alexandries (1985). The Man in the White Sharkskin Suit, de Lucette Lagnado, foi traduzido ao português (O homem do Terno de Panamá/Branco - O êxodo de uma família da antiga cidade do Cairo para o Novo Mundo) por Vera Ribeiro. Ed. Objetiva, São Paulo, 2010. Em hebraico destacou-se Yitzhak Gormezano-Goren, originário de Alexandria, a respeito da qual ele escreveu uma trilogia. Das autoras já nascidas em Israel, devem ser mencionadas: a falecida Ronit Matalon e Orly Castel-Bloom. No Brasil, três autores originários do Egito deixaram as suas impressões em relatos diversos: Alain Bigio, Alberto Moghrabi e Nessim Hamaoui.

${ }^{2}$ O livro foi incluído na Coleção de Obras Representativas da UNESCO. Em 2007, ele foi apontado em Israel como uma das dez obras mais importantes do país desde a criação do Estado. Em 1999, Orly Castel-Bloom foi apontada como uma das cinquenta mulheres mais influentes de Israel.

${ }^{3}$ CASTEL-BLOOM, Orly. Haroman hamitsri. Hassifriyá Hachadashá, Sifrêi Siman Kriá, 2015. A autora ganhou, por este livro, o Prêmio Sapir de 2016, o mais importante prêmio literário do país.
} 
em um tempo contínuo. Trata-se de uma combinação dramática de acontecimentos e detalhes marginais junto com mexericos, hipérboles macabras e satíricas que são capazes de causar grande impacto emocional.

O conjunto compõe uma saga familiar parcialmente autobiográfica, o que é indicado pelo sobrenome de vários dos personagens - Castil - Castelo ou Castilho em português, um nome originário da Espanha de antes da expulsão dos judeus pela Inquisição em 1492. É também uma história de imigração do Egito de dois irmãos, Vita e Charlie Castil, que, quando jovens, no final da década de 1940, depois que foi estabelecido o Estado de Israel, foram membros do ramo cairota do movimento juvenil judaico marxista-sionista Hashomer Hatsair, movimento pelo qual imigraram com suas futuras esposas, Adele e Vivienne, ao Kibutz Ein-Shémer, próximo à cidade de Hadera. A aceitação dos membros egípcios pela população original do kibutz, proveniente da Polônia, foi complexa, mesmo todos sendo seguidores das mesmas linhas ideológicas. Os jovens originários do Egito acreditavam que, num país livre, poderiam externar suas opiniões de forma mais liberal; os de origem europeia, por sua vez, viam os originários do vizinho Egito - cujas famílias eram geralmente bem-postas social e culturalmente no país de origem - como assemelhados a imigrantes provindos de outros países árabes que, por vezes, por serem de nível sócio-cultural-econômico mais baixo não gozaram de uma apreciação suficientemente digna. As duas visões eram falhas,

Para os idealistas irmãos Castil assim como os demais membros egípcios do kibutz, o maior trauma não foi terem sido obrigados a abandonar o país de origem, mas, por causa de uma disputa ideológica, terem sido expulsos do kibutz onde viveram por três anos e onde planejaram passar o resto de suas vidas. A votação para saber se os kibutzim eram "pró" ou "contra" a realização do julgamento em Praga de um alto funcionário do Partido Comunista da Checoslováquia, Rudolf Slansky e mais doze líderes, quase todos judeus, acusados de traição como sendo trotskistas, titoístas, sionistas, foi o motivo para a expulsão. Vinte e três judeus egípcios, marxistas fervorosos, foram expulsos do kibutz por votarem contra a decisão nacional, mas mais sessenta partiram em solidariedade a eles. Como resultado, - a grande ironia da vida deles - a maioria do grupo acaba em empregos administrativos em Tel Aviv que lhes proporcionam um padrão de vida mais alto e confortável do que o de seus antigos colegas de kibutz; ao invés de se tornarem proletários trabalhando nos campos, tornaram-se uma burguesia urbana que remetia ao seu modo de vida no país de origem; as varandas perto do mar de Tel Aviv ou do Rio Yarkon substituíram aquelas que eram voltadas para o Nilo que evoca as nostalgias da infância e juventude. As circunstâncias "antissionistas" de sua saída e seu estigma 
permaneceram um segredo compartilhado. A porção do livro que aborda o kibutz pode ser apreciada como uma sátira aos tempos do idealismo passado.

A aliyá (imigração) para Israel apresentada no romance é insípida e decepcionante, uma jornada de compromisso e expulsão constante, em que os ideais são definidos como um pacto pragmático e desamparo diante de uma realidade passiva, desprovida de continuidade cultural ou integração em um plano mestre ideológico. Enquanto a geração expulsa do kibutz, ainda que carregando para sempre a frustração, se estabelece e se assenta bem em Israel, a geração dos descendentes decai, as filhas dos dois casais são apresentadas apenas por indicativos (a filha mais velha, a filha mais nova, a filha única, prima das anteriores), outras sofrem de doenças autoimunes, da perda de cálcio e da falta de compromisso: promessas transmitidas no leito de morte, cuidado mútuo e de união familiar, enfrentam circunstâncias difíceis e incompetências que impedem o cumprimento das juras. São pessoas sem identidade e sem espinha dorsal. As frustrações em Israel negam a assertiva bíblica de Jeremias: "Naqueles dias não dirão mais: Os pais comeram uvas verdes, e os dentes dos filhos se embotaram.” (JEREMIAS 31:29) A quebra dos ideais dos pais se reflete na incapacitação das filhas.

A saga de Orly Castel-Bloom refere-se à sua família e é narrada a partir das suas experiências e do que herdou. Sem sequências lineares constantes, inclui anedotas sem pertinência alguma com a família, ambientadas em Israel, no Egito ou na Espanha. Ao mesmo tempo em que estas servem como pausas nas tensões das histórias familiares, para criar ambientações assessoras que complementam de modos diversos o espaço e a história de onde vivem ou viveram, dão destaque à posição da narradora, apresentada sempre como "a filha mais velha", a aspectos ou eventos nos países que podem acentuar tanto o cotidiano que flui sem o peso da saga, como histórias pitorescas da vivência e convivência egípcio-israelense nos primeiros anos de relações diplomáticas entre os dois países e nos anos da Revolução Egípcia de 1990 em diante.

No primeiro caso, de proporcionar uma oportunidade de se afastar da história familiar, enquadra-se o causo registrado no capítulo 9, "Hadelpekistit memanéfet" (Alavancamento da atendente) que esboça devaneios e reflexões sobre o imaginado estado de espírito da atendente da loja de conveniência do posto de gasolina da Rua Rokach em Tel Aviv. No segundo caso, quase no final do livro, em que Castel-Bloom se volta ao Egito contemporâneo da derrubada do presidente Hosni Mubarak, a narradora especula sobre como egípcios veem israelenses e, por fim, como o protagonista egípcio não é absolutamente confiável. No capítulo 14, “Aviv hamehumot” (A Primavera dos Distúrbios), que não tem nenhuma relação com a família Castil, 
desenrola-se a mirabolante vida do historiador e guia de turismo egípcio, Farid al-Amrawi, falante do hebraico, desde seu período de estudos arqueológicos, passando pelos anos bem afortunados quando, após o estabelecimento de relações diplomáticas os israelenses afluíam em peso ao país vizinho, aos anos desafortunados que se seguiram, a Revolução Egípcia, o lamentável trabalho no outrora belo zoológico do Cairo, agora em total abandono, o encontro com uma excêntrica milionária judia cairota, Celeste Sanuah, uma quase solitária remanescente da agora inexistente comunidade judaica, uma cabeça e meia mais alta do que ele, suas relações com ela e que culminam com o desaparecimento do mesmo após furtar alguns bens daquela. $\mathrm{O}$ final aponta para o relacionamento falso, o usufruto dos bens alheios, o desligamento, sugerindo a repetição da história do Egito e seus judeus. Não será ousado dizer que até a grande diferença de altura entre ambos pode estar indicando alguma outra grande defasagem entre os dois povos. Neste causo, esta é, em síntese, a trama; nela, a autora se supera ao incluir uma quantidade considerável de comentários acrimoniosos e muito perspicazes em frases breves tanto sobre israelenses, sobre judeus, como sobre a lamentável situação do Egito. Nada é poupado.

Ao tratar da história de sua família, a autora pretendeu, segundo suas palavras em entrevista, registrar a história dos sefarditas, “Ce roman est mon devoir de mémoire sépharade. C'est un hommage à ma tribu, la famille Castil, originaire d'Égypte, mais auparavant d'Espagne, pays d'où ils furent expulsés en 1492 par les instigateurs d'une Inquisition catholique féroce".4

O romance egípcio é a história dos sefarditas de Castel-Bloom. Cada ramo dos sefarditas, em Israel ou em outros locais, tem história própria. A. B. Yehoshua, em seus romances $O$ amante, Cinco Estações e O Senhor Máni tem seus sefarditas europeus. Castel-Bloom tem os seus egípcios, ainda que nem só de sefarditas ela trate, como se lê quando outras origens são frisadas. É sabido que entre judeus do Egito no século XX houve ashkenazitas que se estabeleceram no país após a abertura do Canal de Suez, assim como judeus italianos, judeus orientais e outros que não se enquadram nestas categorias e que há séculos ali viviam, com ou sem passaporte ou documento de identidade egípcio, falantes do árabe.

Uma procedência estranha, relacionada à personagem Vivienne, já no início do livro, é um dos modelos fantasiosos que a narradora descreve:

\footnotetext{
4 “Este romance é o meu dever de memória sefardita. É uma homenagem à minha tribo, a família Castil, originária do Egito, mas anteriormente da Espanha, de onde foram expulsos em 1492 pelos instigadores de uma feroz Inquisição Católica.” Entrevista concedida a Elias Levy. Todas as traduções são de minha autoria. (N.R.)
} 
“(cuj)a família já se encontrava no Egito há séculos, por demasiados séculos, talvez até milênios, porque aparentemente, como sua mãe Flore havia lhe contado, pertenciam àquele clã, àquela única família que não é mencionada na história do povo judeu - aqueles que durante o grande êxodo rejeitaram Moisés, nosso mestre, e permaneceram no Egito como escravos. Somente séculos mais tarde eles foram liberados e se tornaram caçadores selvagens, e quando judeus chegaram ao Egito após a expulsão da Espanha, apressaram-se para se juntar a eles, porque sentiram, de algum modo vago, místico, a antiga afinidade". (CASTEL-BLOOM, 2015, p. 10).

O tema aberrante faz contraponto com os relatos que formam o arsenal genealógico histórico viável da família que Castel-Bloom quis destacar. Da outra extremidade do Mediterrâneo, da Espanha-Sefarad, provém a fantasia sefardita da origem dos Castil. O oitavo capítulo, "Shnat hachazir" (O Ano do Porco) traz a igualmente extravagante aventura da grande família, apegada em parte às plantações de lavanda e respectivo fabrico de sabonetes ou criando e pastoreando carneiros e ovelhas no século XV na localidade de Torre de Mormojón em Castela. Ante a ameaça da Inquisição, sete dos oito irmãos e suas famílias escaparam para a Faixa de Gaza. A história que se sobressai e que é considerada segredo de família, é a daquele irmão que se atrapalhou ao tentar fugir, dá as caras em Portugal onde não encontra afeto por parte dos judeus locais (imigrantes roubam empregos, se usarmos a linguagem atual); na volta à Espanha, converte-se pro-forma, vende a filha Ester como escrava e a recupera. Nesse meio tempo, ela é convertida três vezes. Para camuflar a identidade judaica, ela passa a ser a provedora da família no ofício de criadora de porcos que aprendera enquanto escrava (período em que ela se absteve de cuidar deles nos sábados). O capítulo apega-se a um (pseudo-) estudo mais do que duvidoso de um certo Jonathan Tzadik, segundo o qual 1492 - ano da expulsão dos judeus da Espanha e das descobertas de Colombo - foi um ano especialmente estranho na história do país porque foi "o ano do porco". A história da criadora de porcos é uma das diversões suscitadas por este livro; Ester acabou por ser obrigada a usar o sambenito, o traje acusatório dos condenados pela Inquisição. Os cheiros e sentimentos fortemente contrastantes entre lavanda e porcos causam rompimentos na família e apontam de forma nítida para a situação trágica dos conversos e os opostos entre as práticas religiosas camufladas e ostensivas. Estes relatos excêntricos causam espécie semelhante aos horrores disseminados nas obras mais famosas de Castel-Bloom: Dolly City e Chalakim enoshiim (Partes Humanas). Como um detalhe a mais nesta estranha história, há um certo rabino Isaque $\mathrm{Abuab}^{5}$, que não chega a parte alguma porque morre de peste no caminho.

\footnotetext{
${ }^{5}$ Paródia ao nome do Rabino Isaque Aboab da Fonseca que viveu em Recife no século XVII.
} 
Somadas já as diversas origens da família Castil do Egito, cumpre somar as diversas saídas dos hebreus ou judeus daquele país. Ao obviamente conhecido relato bíblico com a famosa fuga conduzida por Moisés, acresçam-se as do século XX, quando os Castil partem. Assim que ocorreu a independência de Israel, em 1948, judeus suspeitos de atividade sionista ou comunista foram presos e, em 1949, expulsos. Todavia, nos anos seguintes, como no texto bíblico, os judeus - ao menos a maioria deles - não foram expulsos, mas as circunstâncias extremamente adversas os levaram a partir. Em 1956, em sequência à Campanha do Sinai, judeus foram presos, seus bens sequestrados, seus passaportes receberam o carimbo de "sem direito a retorno". Dos cerca de oitenta mil que viviam no país, menos da metade se dirigiu a Israel. Cerca de quinze mil vieram ao Brasil. Não foi preciso um Moisés para conduzi-los.

O Rio Nilo de Moisés é importante fator em um dos causos narrados do personagem Vita Castil. O capítulo 7, "Mahapechá” (Revolução), que trata da reviravolta contra as miseráveis condições de vida do país, apresenta os depauperados campônios egípcios aos membros do Hashomer Hatzair. As diretrizes do movimento sionista despertam em Vita Castil também o sentimento nacionalista egípcio. Como egípcio nacionalista, arriscava a vida participando das manifestações contra o regime monárquico do Rei Faruk e, como sionista, contrabandeava judeus para fora do país.

Este Moisés contemporâneo precisou sair das águas do rio para se salvar, e a ajuda que obteve foi de ordem diversa da do ilustre mestre bíblico. Os que procuraram abrigo durante uma manifestação na ponte Abbas, foram para ali escorraçados e quando a polícia contra-atacou os revoltosos encurralados, sobrepôs-se a eles ordenando que a ponte levadiça repleta de homens que procuravam abrigo ou fuga fosse içada. No alto, os revoltosos tornaram-se alvo mais fácil para a força repressora. A única alternativa era saltar de vinte metros de altura e eventualmente se afogar. Entre as exclamações de Mactub (está escrito) apreendidas do lamento dos campônios que assim expressavam o sentimento de inércia ante a exploração e a miséria e que Vita Castil, mau nadador, proclama ao pular para a água e a frase de incentivo que lhe é berrada por um egípcio quando emerge e é estimulado a fugir nadando, "Ya'alla, ya'alla, Kilimanjaro", é a este mote salvador que ele se apega. Como bom estudante de geografia que tinha sido, menciona aí como fortaleza todos os maiores picos que tinha decorado: "À sua direita encontravam-se o Kilimanjaro, Everest, Mont Blanc, Ojos del Salado e Aconcagua, e à sua esquerda Mactub". Entre fé e esperança, entre aceitar o destino ou lutar, é assim que Vita se salva. Mais uma vez o destino dos judeus esteve ligado ao Nilo. (P. 80) Não é preciso invocar ajuda divina. 
Segundo a Bíblia, os descendentes de Jacó amargaram os anos do deserto e amarguraram a vida do seu condutor. ${ }^{6} \mathrm{O}$ líder precisa lhes ensinar que há algo mais precioso que as panelas de carne das quais estão saudosos. Os Castil do século XX, mesmo tendo se amargurado de outros modos, não deixam, todavia, de lembrar o conforto e prazer de viver às margens do rio. Diversamente de escritos de autores israelenses sefarditas ou orientais, Castel-Bloom não evoca a antiga pátria em tom choroso e com sentimentalismo.

Pouco antes da Revolução Egípcia de 2011, a autora foi conhecer o Egito. Não se pode inferir daí quanto a visita inspirou ou influenciou seu $O$ Romance Egípcio. Sentiu-se magnificamente bem no país, livre, conforme declarou na entrevista já citada, até que, em um centro acadêmico onde deveria falar, entendeu que o Egito não quer os israelenses, ou seja, os israelenses judeus. Ali, ao se declarar originária de Israel, passou a ser totalmente ignorada, alijada. O Egito pode ser estar inscrito em seu DNA e nos dos personagens do seu romance, mas o Egito não os quer. Algum dia, os judeus sairão definitivamente do Egito. Ou não. Hoje, somente seis mulheres judias com idade superior a 65 anos vivem no país.

\section{REFERÊNCIAS BIBLIOGRÁFICAS}

CASTEL-BLOOM, Orly. Haroman hamitsri (O Romance Egípcio). Tel Aviv, Hassifriyá Hachadashá, Sifrêi Siman Kriá, 2015.

LEVY, Elias. Entrevue avec l'écrivaine israélienne Orly Castel-Bloom. In LVS La Voix Sépharade. Quebec, Avril 2017. Disponível em: <http://lvsmagazine.com/2017/04/entrevueavec-lecrivaine-israelienne-orly-castel-bloom>. Acesso em 23/10/2018.

\footnotetext{
${ }^{6}$ E os filhos de Israel disseram-lhes: Quem dera tivéssemos morrido por mão do Senhor na terra do Egito, quando estávamos sentados junto às panelas de carne, quando comíamos pão até fartar! Porque nos tendes trazido a este deserto, para matardes de fome a toda esta multidão. (Êxodo 16:3).
} 